\title{
WILLIAM CHESELDEN (1688-1752) Y GERARD VAN DER GUCHT (1695-1776). LA TÉCNICA QUIRÚRGICA, EL ARTE DE LA ESTAMPA Y LA CONTROVERSIA EN EL LIBRO UROLÓGICO DEL SIGLO XVIII.
}

Juan José Gómiz León.

Servicio de Urología. Hospital Clínico Universitario "San Carlos". Madrid. España.

Resumen.- Se revisa la obra impresa del anatomista y cirujano inglés William Cheselden prestando atención preferente a los grabados calcográficos que la ilustran, mayoritariamente estos de autoría de Gerard van der Gucht y del miniaturista Jacob Schijnroet, reivindicándose el valioso concurso de dibujantes y estampadores y su imprescindible aportación figurativa para explicar y facilitar al lector la comprensión de los textos, resultando las imágenes a tal objeto de tanta importancia como aquellos, y aportando a la obra un sensible valor artístico.
Así mismo, se expone la agria polémica que provocó en la sociedad médico-quirúrgica inglesa del tiempo, muy particularmente en la litotomista o "urológica", la publicación de la obra intitulada "The High Operation for the Stone" de W. Cheselden, que coincidió cronológicamente con la segunda impresión de la "Lithotomía Douglasiana" de John Douglas, y las acervas críticas que se dispararon contra Cheselden, uno de cuyos máximos exponentes fue la publicación del libro titulado "Lithotomus Castratus", en el cual, revisadas puntualmente por su autor ambas obras, cotejadas, detalladamente analizadas y confrontadas una y otra, señaló públicamente a Cheselden ser plagiario de Douglas.

Palabras clave: William Cheselden. Gerard van der Gucht. John Douglas.

Summary.- We review the printed work of the English anatomist and surgeon William Cheselden, with special attention to the chalcographic engravings which illustrated it, mainly those by Gerard van der Gucht and the miniaturist Jacob Schijnvoet, vindicating the valuable collaboration of illustrators and printers and their essential figurative contribution to explain the texts and make them easier to understand for the reader. These images were as important as the texts and contributed considerable artistic value to the work.

Likewise, we present the bitter controversy caused in the English medical-surgical society of the time, most especially in the lithotomist or "urology" community, by the publication of the work entitled "The High Operation for the Stone" by W. Cheselden. The publication coincided chronologically with the second edition of "Lithotomia Douglassiana" by John Douglas, and the scathing 
criticism hurled against Cheselden, one of the prime examples of which was the publication of the book entitled "Lithotomus Castratus"; in the book, both works were revised meticulously by its author, collated, analysed in detail and compared against each other, publically indicating that Cheselden plagiarised Douglas.

Keywords: William Cheselden. Gerard van der Gucht. John Douglas.

\section{INTRODUCCIÓN}

Fue William Cheselden (1) un reputado cirujano inglés (Figura 1) que alcanzó gran notoriedad tanto en su país, Inglaterra, como en la influyente y poderosa Francia de su siglo. Nació Cheselden el 19 de octubre de 1688 en Somerby, del lugar llamado Burrow on the Hill enclavado en el condado de Leicestershire. Todavía muy joven, a partir de 1703 inició estudios de Anatomía en Londres al lado de William Cowper, estudios que simultaneó con el aprendizaje de la cirugía junto a James Ferne.

En 1711 obtuvo la pertinente licencia expedida por el gremio, cofradía o sociedad de Cirujanos-Barberos que le habilitaba para el ejercicio de su profesión (o arte). Era ya por entonces lector de Anatomía, comenzaba su andadura quirúrgica en el St. Thomas Hospital, y había sentado plaza e ingresado en la Royal Society en calidad de "fellow". Fue por esta época de su vida, contando apenas los 25 años de su edad, cuando dio a la imprenta su "Anatomy of the Human Body" (William Bowyer impresor. Londres. Año de 1713), obra ilustrada con 40 excelentes grabados y que sobrevivirá vigente casi un siglo, hasta que en 1806 salga de las prensas la décimosexta, y última, edición.

Además de en el St. Thomas, prestó Cheselden sus servicios en la Westminster Infirmary y en el St. George Hospital, ganando prestigio y fama como hábil litotomista, en un principio ejecutando con pasmosa destreza y agilidad la cistolitotomía por vía hipogástrica que, no obstante y sin que conste razón concreta, abandonará por la talla perineal lateral según su personal técnica.

De 1723 data la primera impresión de su texto "The High Operation for the Stone" (John Osborn impresor. Londres. Año de 1723), que contenía 17 bellísimas estampas (Figuras 2 y 3 ), obra que coincidió con la segunda impresión de la "Lithotomía Douglassiana", que había aparecido por vez primera en Londres, año de 1720, y que, o tal vez pasó algo desapercibida o bien la tirada fue muy corta, cuyo autor, el cirujano John Douglas (h. 1680-1743), era hermano del igualmente cirujano James Douglas (1675-1742).

A partir de 1733, Cheselden pasó a desempeñar su actividad en el Royal Hospital de Chelsea, y a dedicar sus esfuerzos y recursos pecuniarios a la que deseó convertir en su obra más célebre, la "Osteographia, or the Anatomy of the Bones", que ese mismo año le imprimió en formato gran folio William Bowyer en Londres. Para las bellísimas ilustraciones del texto recabó de nuevo, tal como hiciera para su "Anatomy", el concurso de quien era, si no el mejor, sí uno de los principales y más afamados dibujantesgrabadores de la Inglaterra de entonces, Gerard van der Gucht (1695-1776), así como el del miniaturista Jacob Schijnroet (1685-1733). Pero el tratado, con 56 preciosas estampas a buril sobre plancha de cobre (calcográficos), tan magnífico como de elevado precio, resultó un fracaso comercial y no colmó las expectativas que puso en él su autor.

Además de su actividad quirúrgica, docente y divulgadora, impulsó Cheselden la separación de

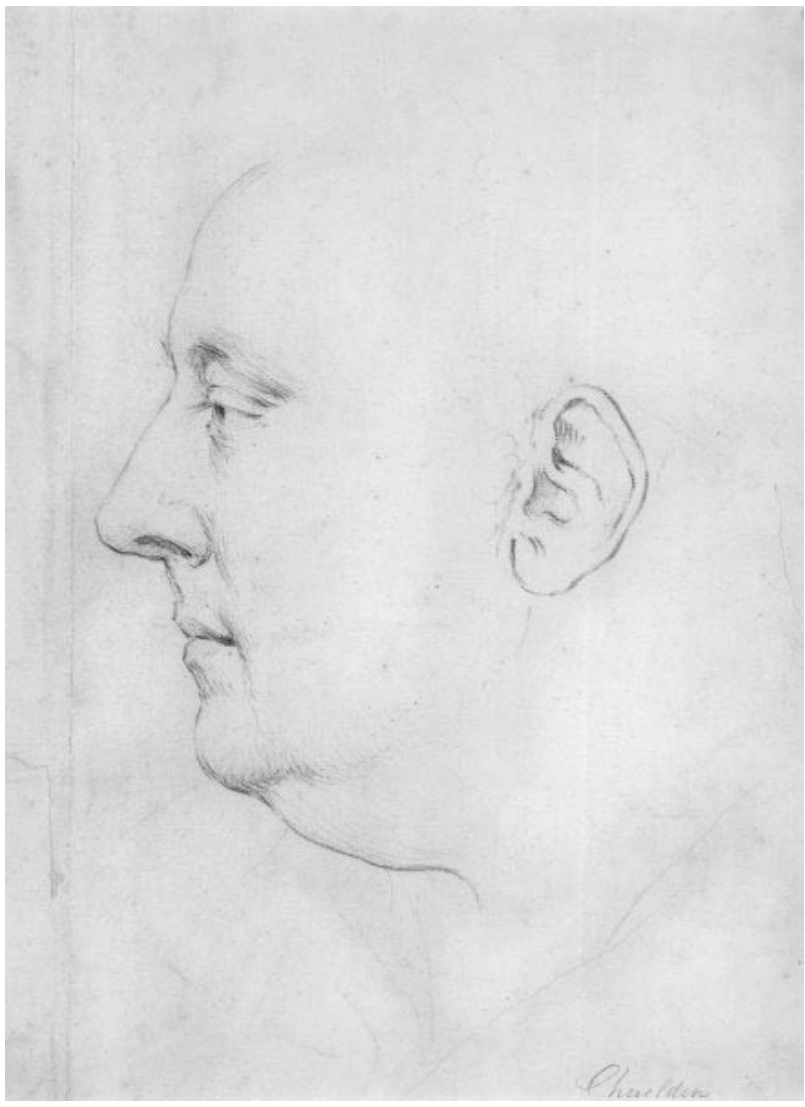

FIGURA 1. William Cheselden. Retrato a grafito por Gerard van der Gucht. 
la cirugía científica y facultativa del empirista gremio de los cirujanos romancistas-barberos, integrado por prácticos que si bien más o menos expertos en su arte, carecían de estudios fundamentales de Anatomía y Medicina; éstos actuaban simplemente porque conocían cómo operar, mientras que aquellos, por qué, cómo y conforme a cuáles fundamentos.

Siguiendo el espíritu de las "luces" dieciochescas, del "Enlightenment" que iluminó su siglo y que en Inglaterra alumbraron con relativa anticipación respecto a la católica Europa continental, Cheselden culminó su empeño en colaboración con John Randy para fundar en 1745 la Company of Surgeons, corporación precursora del Royal College of Surgeons, el cual abrirá los nuevos horizontes del saber quirúrgico británico contemporáneo. Pero ha de indicarse, al respecto de la escisión entre cirujanos y "romancistas" que propugnó y remató con éxito Cheselden, que en su origen existió un determinado conflicto de competencias entre el cirujano-anatomista y el gremio de Cirujanos-Barberos, por actuar Cheselden independientemente de aquel, impartir lecciones y demostraciones de anatomía, tanto públicas primero, como particulares después, en su propio domicilio, y conseguir cadáveres para su estudio (y beneficio) personal, en detrimento y menoscabo del gremio (2).

Falleció el célebre Cheselden el 10 de abril de 1752 en Bath, inhumándose sus restos mortales en el camposanto aledaño al Hospital de Chelsea, donde aún hoy continúa honrándose su memoria y custodiándose su instrumental operatorio.

Gerard van der Gucht (1695-1776) (3) aprendió el oficio de grabador-estampador de su padre, Michael (1660-1725), y dibujo con el pintor de origen francés Louis Chéron (1660-1713) en la Great Queen St. Academy de Londres, perfeccionando la

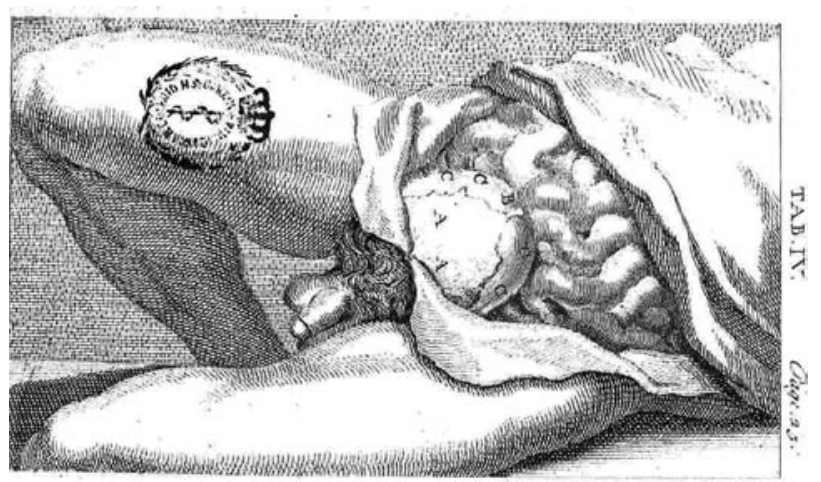

FIGURA 2. Traitaise of High Operation (W. Cheselden), plancha IV (G. van der Gucht). técnica de la estampa conforme a la magistral escuela francesa (Figuras 4 y 5). Trabajó Gerard para comerciantes y merchantes de pintura, quienes para divulgar y publicitar sus fondos, así como para difundir las imágenes de las pinturas, debían recurrir al único soporte entonces conocido, el dibujo y estampado de las obras. E igualmente para libreros e impresores, heredando el taller que le dejó su padre al fallecer. El hijo de Gerard, Benjamin (1753-1794), dará continuidad, llegado su momento, a la secular empresa familiar y saga artística de los van der Gucht.

\section{DISCUSIÓN}

La asociación de autores, sean estos científicos o literarios, dibujantes ilustradores, impresores y libreros, era común en el siglo XVIII, trabajando todos

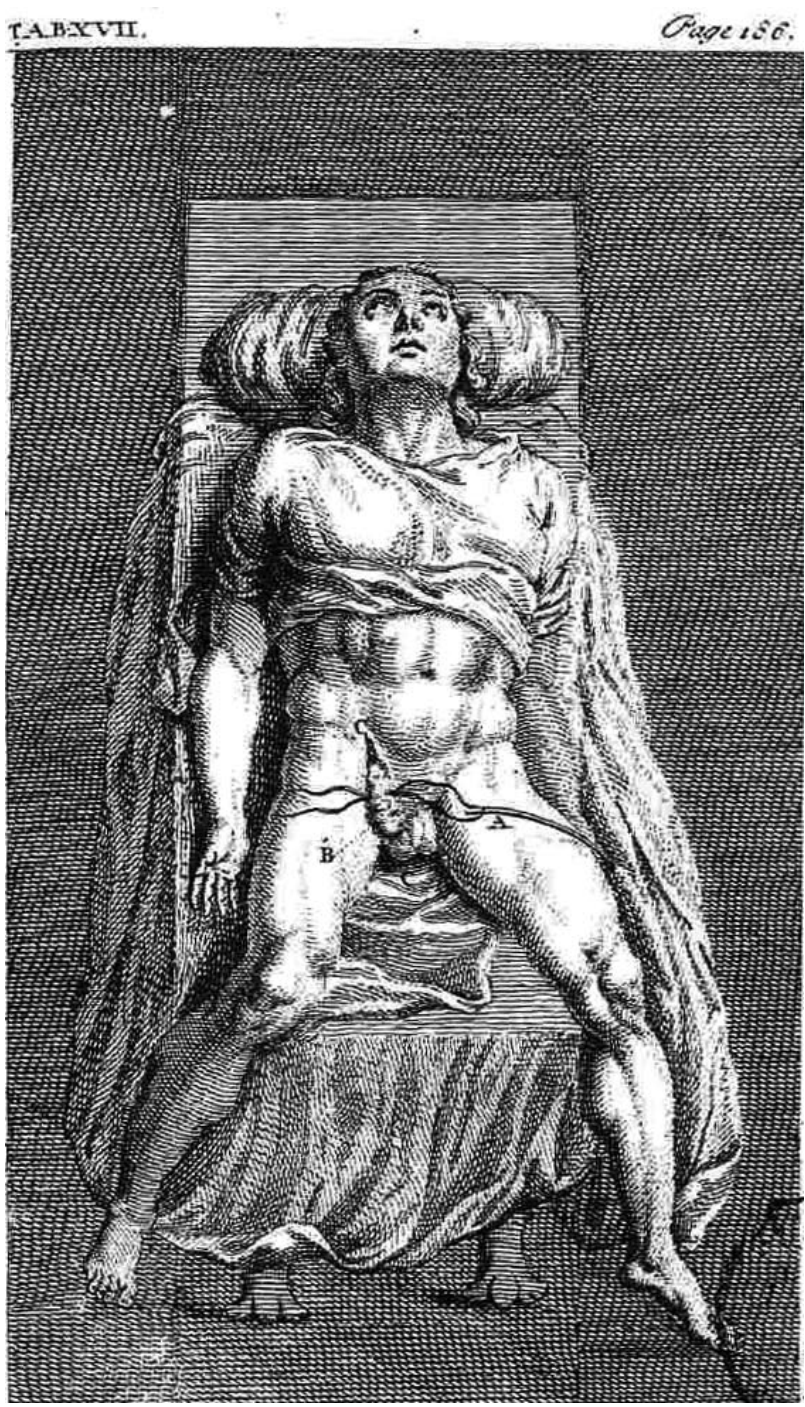

FIGURA 3. Traitaise of High Operation (W. Cheselden, 1723), plancha XVII (G. van der Gucht). 
con el objetivo de llevar al público la obra impresa, en muchas ocasiones previa suscripción, y rentabilizar con su difusión el esfuerzo intelectual y artístico realizado, así como la inversión efectuada. Se imprimía "a costa de", contando con las pertinentes licencias $y$, en algunas naciones, el "nihil obstat" de las autoridades religiosas.

Al lápiz, al buril, a la ruleta y al tórculo de Gerard van der Gucht se deben, por ejemplo, la mayoría (otros son de autoría de Jan van der Bank) de los grabados que ilustran la ortográfica y gramaticalmente defectuosa, tanto en el título como en el texto, pero bellísima por sus estampas, edición inglesa (en lengua española) en cuatro tomos y cuarto grande realizada por don Pedro Pineda "Vida y hechos del ingenioso hidalgo don Quijote de la Mancha", impresa en Londres por J.R. Tonson, año de 1738, más conocida entre los bibliófilos como "edición de lord Carteret" o "Quijote de Carteret", que fue el "Quijote" ilustrado más importante hasta que vino a superarlo la extraordinaria edición española auspiciada por las Reales Academias de la Lengua y de las Tres
Nobles Artes de San Fernando, el celebérrimo "Quijote de la Academia" del impresor don Joaquín lbarra, Imprenta Real, Madrid, año de 1780 (4).

Sin embargo, como nota curiosa, el retrato de don Miguel de Cervantes que ilustra el frontis del "Quijote" de Tonson no es de van der Gucht ni de van der Bank, sino del grabador George Vertue según dibujo de William Kent, desconociéndose cómo tuvo acceso el artista inglés a la efigie del inmortal escritor, idéntica a un retrato, si es que no la copió directamente del original que se supone de la autoría de Francisco Pacheco o de Juan de Jáuregui y Aguilar, por entonces ya perdido o en paradero ignorado, cuya copia realizó Alonso del Arco y que era propiedad del sevillano conde del Águila.

Se realizaron en España profundas investigaciones encaminadas a acreditar y confirmar, o refutar, si aquel retrato de la edición inglesa correspondía, o no, con la verdadera efigie de Cervantes, concluyéndose muy sorprendentemente que en efecto sí lo era (5).

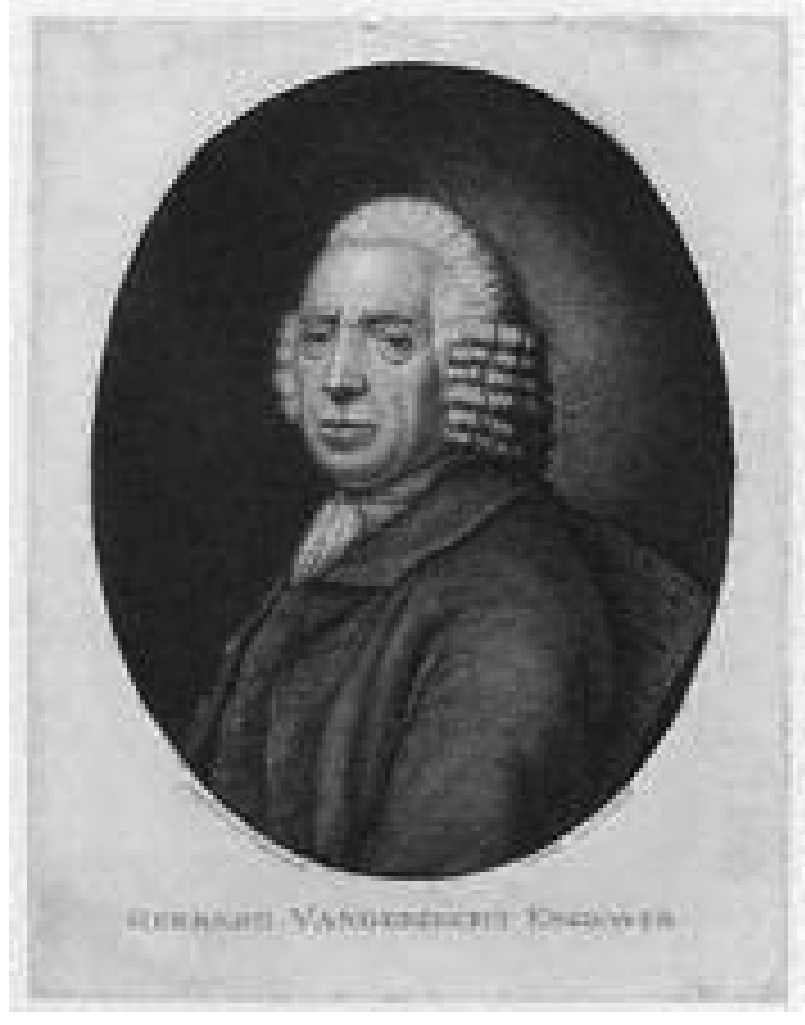

FIGURA 4. Gerard van der Gucht. Estampa de su retrato por James Caldwell de Benjamin van der Gucht. National Portrait Gallery (Inv nº NPG D 18989 ). Londres. GB.

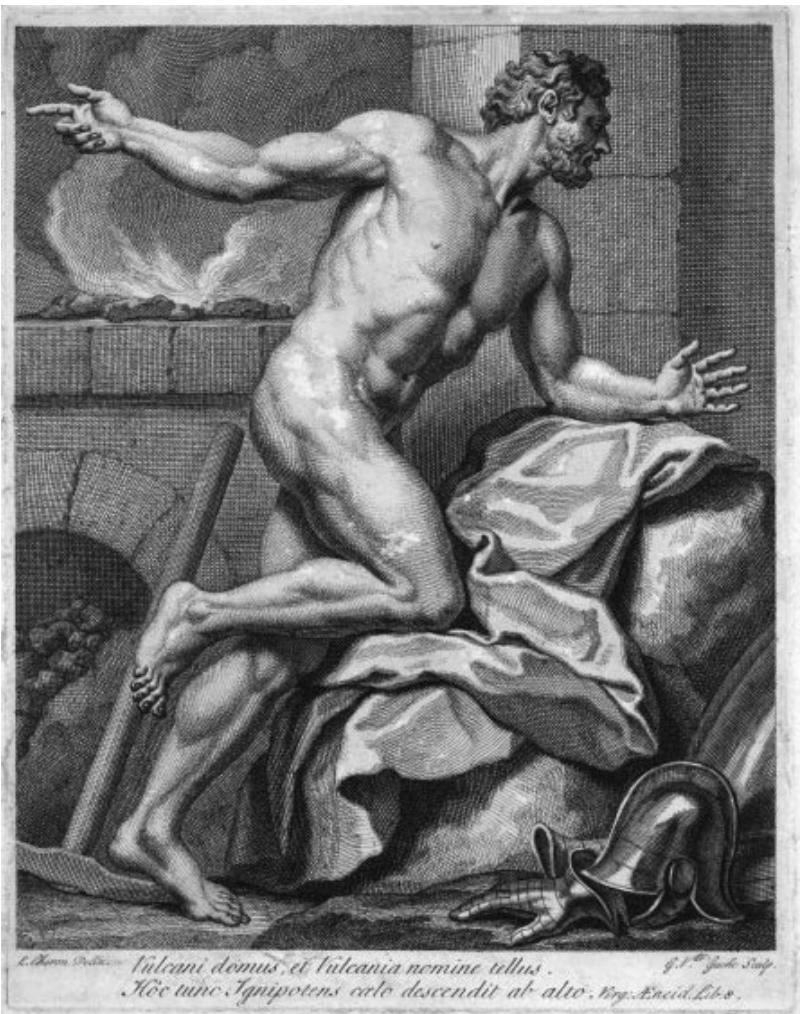

FIGURA 5. Vulcano. Estampa de la misma pintura de Louis Chéron por G. van der Gucht. Royal Academy of Arts. Londres. GB. 
En todas las obras que a Cheselden le imprimió William Bowyer aportó Gerard van der Gucht su talento artístico como ilustrador. Si bien es muy probable que Cheselden tuviera buena mano como dibujante, no sería tal razón suficiente para atribuirle (6), además de los textos, la autoría de las imágenes. Pasar el dibujo original a la plancha de cobre valiéndose del buril, rayar la superficie del metal, perfilar el motivo, difuminar las sombras, entintar, estampar pruebas de estado, corregirlas e imprimir el grabado definitivo, exige unos conocimientos técnicos que van más allá de las dotes artísticas de un buen dibujante aficionado. Van der Gucht, Schinjnroet, y posiblemente también Cheselden, utilizaron el recurso o ayuda de precisión, tal como aparece en los frontis del "Anatomy" y de la "Osteographia", que les brindaba el empleo de la "cámara oscura", antecedente remoto de la fotografía. Un instrumento el suyo portátil, cerrado, apto para trabajar con luz natural, provisto de un objetivo (lente) que proyectaba invertida la imagen sobre un espejo, muy precisa, la cual el artista calcaba sobre un fino papel "de cebolla" o copiaba directamente.

Si bien en la "Osteographia" y en la "Anatomy of the Human Body" (7) consta debidamente la colaboración artística de van der Gucht, curiosamente no se reseña ésta en el controvertido "Traitaise of the High Operation for the Stone" (8), cuyos grabados anatómicos del primero al séptimo, el décimo sexto (caso de Margaret White, página número 177 sin paginar), y el décimo séptimo (caso de Robert Heysham, página número 178 bis, sin paginar), por lo menos, son indudablemente de la mano de van der Gucht. Cheselden cambió de impresor (Osmond por Bowyer) para imprimir su segunda obra, el "Traitaise", posiblemente apremiado por la necesidad de sacarlo de la imprenta con celeridad, quizá motivo éste por el cual se omitiera el nombre del grabador, si es que no hubo otros de mayor peso o conveniencia.

Pero esta obra, tan señera en la Historia de la Urología y tantas veces citada, no contribuyó precisamente a incrementar la fama de su autor, si bien, afortunadamente para él, solamente la empañó, introduciéndole en una desagradable polémica.

Quizá Cheselden, profesional brillante arropado por su prestigio, albergara realmente, como sus detractores y críticos propugnaron, atribuirse progresos técnicos que le eran ajenos, y además con intereses espurios. Dedicó su "Traitaise of the High Operation" al doctor Richard Mead, "fellow" del College of Physicians de Londres y miembro de la Royal Society, por el estímulo de que de él recibió
(The succes of these operations being greatly owing to the encouragement you gave me), para a continuación puntualizar (Prefacio, p., VII) que, por los años de 1717-1718, James Douglas había presentado una comunicación a la Royal Society en la que explicó, sobre bases anatómicas, cómo sería posible realizar sin daño la talla hipogástrica, pero que nadie lo había llevado a la práctica (bien por no confiar en la técnica, bien por no arriesgar el prestigio y la reputación con ella), hasta que su hermano John, "un buen anatomista, y antiguo maestro (de Cheselden) en el St. Thomas", la ejecutó (omitiendo aquí Cheselden la fecha). Pero que, en opinión del autor (Cheselden), la técnica expuesta y realizada por James y John Douglas respectivamente era exactamente igual a la de Rosset (y aquí sí remite Cheselden a su lector al texto de John Douglas "Lithotomia Douglassiana", suponemos naturalmente que al datado en 1720), cirujano a quien Cheselden atribuye el honor de haber sido el primero en llevarla a cabo

1

Lithotomus Caftratus; O R, 114.

Mr. CHESELDEN'S

TREATISE on the

HIGH OPRRATION for the STONE, Thoroughly Examin'd, and plainly found to be Litrhotomia Dougl assian a, $\sigma^{\circ} c^{\circ}$ Under another Title: In a LET T E R to Dr. John Ar buthari: W I T H A N APPENDIX, Wherein both Authors are faity segespar'd. To which is added,

- A Word of Advice to Surgeons.

Neque ab altis foripta vindicanda nobis: qusia maxime iniquit atis opus eft anferre feriptori glorians, gue ad illom pertineat. Jamb. in Nicom. Arith. Sunt mea quidem fententia plufquam plagiariorwin tena digni, qui bujufsnodi furtis delectantur cे thena dagn, qu laborens aliesum attribatuat.

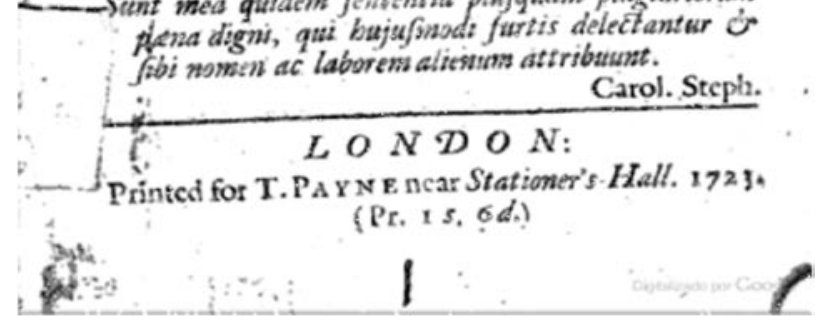

FIGURA 6. "Lithotomus castratus..." (Robert Houston). T. Payne impresor. Londres, 1723. 
de manera reglada en 1590 (puesto que Pierre Franco efectivamente la efectuó con anterioridad a Rosset en un niño, pero como recurso extraordinario y desesperado al no poder extraer el gran cálculo vesical a través del periné). Y que Douglas, tal como él mismo había manifestado, ni había oído ni leído nada acerca de Rosset hasta que se lo citó Cheselden.

Infiriendo de todo ello en el Prefacio (pp., VII y IX) del "Traitaise" que ninguno de los dos (ni Cheselden ni Douglas) podían considerarse descubridores originales del método, que no era, por tanto, su intención apropiárselo sino únicamente exponerlo, aunque levemente modificado, a partir del descrito por Rosset, pues cierto era que algunos de los pasajes de la obra rossetiana eran confusos y no se comprendían suficientemente bien.

La cuestión de si Cheselden se justificaba en parte, excusaba veladamente, o exponía sinceramente sus tesis en las primeras páginas de su obra, resulta hoy difícil dilucidar. Pero es cierto que muy poco tiempo después que su libro, en el mismo año de 1723, saliera al público, aparecía en Londres e impreso por T. Payne otro que llevaba por título: "Lithotomus castratus; or míster Cheselden's Treatise on the High Operation, thoroughly examin'd, and plainly found to be Lithotomia Douglassiana, etc., under another title: in a letter to Dr. John Arbuthnot, with and appendix, wherein both authors are fairly compar'd, to which is added a word of advice to surgeons" (Figura 6), firmado por Robert Houston (quizá pseudónimo de Douglas), censurando tajantemente tanto la indecencia y deshonestidad de Cheselden como su libro, "que no es una obra nueva ni original, sino que pretende ocultar la del hombre que primero realizó la operación en Inglaterra" (Lithotomus castratus..., p., 5), y que después de cotejarlo y compararlo detalladamente con la "Lithotomia Douglassiana, or a new method of cutting for the stone, first practiced by John Douglas, surgeon" (curiosamente con la impresión de 1723, que sin duda debió anticiparse semanas o meses al "Traitaise" de Cheselden), concluyó Houston que el de Cheselden era una mera copia, un palmario plagio del de Douglas.

Por lo tanto, algunos pocos años antes de 1720 John Douglas realizaba con seguridad la talla hipogástrica. Y con relación a su "Lithotomia Douglassiana" debe puntualizarse que la primera impresión la realizó T. Woodward en Londres en 1720, y la segunda, de la que algunos autores dudan (9), en 1723, impresa por C.Rivington, J. Lacy y J. Clarcke, fechándose la Dedicatoria el 31 de octubre de 1722.
No obstante la polémica, y atraído por la fama de Cheselden, no por la de Douglas, se desplazó a Londres desde París el célebre cirujano Sauveur-Françoise Morand (1697-1733) para aprender la litotomía hipogástrica, elogiar al cirujano inglés cuando regresó a Francia, y publicar a su vez su propio correspondiente "Traité de la Taille au Haut Appareill" (París, 1728). En parte quizá por la agria polémica y acerva crítica, Cheselden abandonó la vía suprapúbica para recuperar y modificar la vía perineal lateral que John Rau (1658-1708) realizó en Leyden, muy similar a la de Jacques de Beaulieu (1651-1714), de quien la aprendió, precisamente la técnica que se impuso definitivamente, salvo excepciones, durante el siglo XVIII, y que fue la adoptada por los Reales Colegios de Cirugía Españoles.

Pero la rivalidad entre Cheselden y Douglas se extendió de la talla suprapúbica también a la perineal lateral, que ambos modificaron, y cuya historia James Douglas expuso en su "History of the lateral operation for the stone" (Londres, 1726; traducción latina en Leyden, 1728 y traducción en lengua francesa en París, 1734), obra a la que señorial y elegantemente añadió cinco años después un apéndice intitulado: "An appendix to the history of the lateral operation for the stone, containing mister Cheselden's present method of performing it", impresa en Londres, año de 1731, en la cual pueden admirarse los bellos grabados del instrumental que diseñó y usaba Cheselden para tal vía, y cuyo autor no era otro que Gerard van der Gucht.

\section{CONCLUSIÓN}

El grabado calcográfico, la estampa, fue hasta el advenimiento de la litografía y posteriormente la fotografía, la única técnica apta para la reproducción multiplicada y difusión de las imágenes.

Autores e impresores recabaron la imprescindible colaboración de los artistas ilustradores para facilitar la comprensión de los textos, siendo los libros, en consecuencia, obras colaborativas cuyas imágenes complementan la palabra escrita, la embellecen y añaden un valor artístico a su información técnica o su calidad literaria.

La difusión de los conocimientos y la lícita reivindicación de su original autoría conllevan naturalmente implícitos tanto el prestigio como el beneficio profesional y crematístico, no estando exentos de la lícita competencia, el sincero orgullo y la digna ambición, pero que en ocasiones derivan en conflicto, ensoberbecimiento vanidoso e interés espurio, motores de polémicas cuyos frutos no siempre son estériles, tal 
como demostraron John Douglas con su "Lithotomia Douglasiana", W. Cheselden con su "Traitaise of the High Operation", y James Douglas con su "An appendix to the history of the lateral operation", obras las dos últimas para las que, al margen de controversias, ofreció su polivalente concurso artístico Gerard van der Gucht.

\section{BIBLIOGRAFÍA Y LECTURAS}

\section{RECOMENDADAS (*lectura de interés $y^{* *}$ lectura fundamental)}

1. http://www.faqs.org/health/bios/70/William-Cheselden.html

2. Maganto Pavón E, Clemente Ramos L, Carrera Puerta C. Hitos en la Historia de la Urología. Pulso Ediciones S.A. Barcelona, 1999; 3(9):14-15.
3. http://npg.org.uk/live/search/portrait.asp?LinkID $=\mathrm{mp} 08063 \& \mathrm{rNo}=4 \& \mathrm{role}=\mathrm{art}$

4. Báez E. La gran edición del Quijote de Ibarra. Anales del Instituto de Investigaciones Estéticas. 2006; 23(88):149-67.

5. Calvo Serraller F. Ilustraciones al Quijote de la Academia por varios dibujantes y grabadores de la Imprenta de Joaquín Ibarra. Turner. Madrid, 1978.

6. Ballesteros Sampol JJ. William Cheselden, singular litotomista y gran ilustrador inglés del Siglo XVIII. Arch. Esp. Urol. 2007; 60(7):723-9.

7. $12^{\circ}$ edición, Londres, 1784. Biblioteca Marqués de Valdecilla. Madrid. Signatura BH FG 862.

8. $1^{a}$ edición, Londres, 1723. Biblioteca Marqués de Valdecilla. Madrid. Signatura BH MED B990.

9. Van Strien K, De Withlaan W. A medical student at Leiden and Paris, William Inclair (1736-1738), part II. Proceedings Royal College of Physicians Edimburgh (Proc. R. Coll. Physicians. Edim), Cita bibliográfica número 59. 1995; 25:487-94. 